\title{
On the prevalence of iron deficiency in children and adolescents with growth retardation
}

\author{
Arash Rahbar* and Arian Hajian
}

School of Medicine, Student Research Committee, Babol University of Medical Sciences, Babol, Iran

\begin{abstract}
Iron is a fundamental micro-element in body. Iron deficiency is the most prevalent nutritional deficiency around world. Iron deficiency can disarrange physical growth and neurocognitive development of children thorough different ways such as decreasing oxygen transport capacity, decreasing energy production and decreasing the appetite. The aim of this study was to evaluate iron deficiency prevalence in children between 6-18months old in Babol, Iran. This cross sectional study was performed on 100 children and adolescents with growth retardation in Babol. Weight and height of children was measured and comparing with the growth curve indices, $\mathrm{Hb}$ and mid MCV of children in percentile Height and weight lesser than 3 was evaluated. In this study, prevalence of anemia in growth retarded children was 35.9\% whereas prevalence of microcytic anemia was 20\% followed by iron deficiency prevalence of $1.6 \%$ and 25\%. Average of ferritin level decreased with increasing of severity of growth disorder in children. The results of this study suggest that treatment of growth retarded children with iron supplements can improve their growth. Because data about prevalence of IDA in Iranian children is limited, we suggest further studies to be performed to define an average range of iron concentrations in accordance with other micro-elements such as zinc and copper in children of this area.
\end{abstract}

KEY WORDS: GROWTH RETARDATION, CHILDREN AND ADOLESCENTS, IRON DEFICIENCY ANEMIA

\section{INTRODUCTION}

Iron deficiency is a worldwide problem during life, but infants are especially susceptible to development and complications of iron deficiency (Akramipour et al., 2008). Iron deficiency during first two years of a child life can cause irrecoverable deficits in cognitive devel-

\section{ARTICLE INFORMATION:}

*Corresponding Author: arsah.rahbar@gmail.com Received $20^{\text {th }}$ July, 2017

Accepted after revision $29^{\text {th }}$ Sep, 2017

BBRC Print ISSN: 0974-6455

Online ISSN: 2321-4007 CODEN: USA BBRCBA

Thomson Reuters ISI ESC and Crossref Indexed Journal

NAAS Journal Score 2017: 4.31 Cosmos IF: 4.006

๑ A Society of Science and Nature Publication, 2017. All rights reserved.

Online Contents Available at: http//www.bbrc.in/

DOI: $10.21786 / \mathrm{bbrc} / 10.3 / 38$ opment, and also other potential adverse effects(Black et al., 2013, Victora et al., 2008) 2013, Victora et al., 2008. Iron requirements of infants under six months old, are generally not well determined, since it is difficult to estimate the demands in infants which exclusively eat breast milk (Bender, 2003) Assumed that most of newborn infants are greatly protected from iron deficiency 
by the birth iron stores, usually iron deficiency is not considered in infants below six months old. However, iron deficiency (ID) and iron deficiency anemia (IDA) can be observed, in the range of $0 \%-15 \%$ (ID) and $0 \%-4 \%$ (IDA) in six-month-old infants around the world (Ziegler et al., 2009, Nguyen et al., 2017b).

Older infants (up to 24 months old) are at higher risk of ID and IDA than younger one. Infants are susceptible to the effects of low iron levels, even before the first moments of birth: low iron stores at birth have been associated with iron deficiency and also elevated risk of growth retardation and cognitive developmental disorders later in infancy (Ziegler et al., 2009, MacQueen et al., 2017).

Iron deficiency developing in infancy and leads to IDA has similarly been associated with bad cognitive, behavioral and growth problems; the consequences of iron deficiency without IDA are not clear (Kazal Jr, 2002 Domellöf et al., 2014, Mamabolo and Alberts, 2014, Ritu et al., 2017).

In Iran, there may be not an ordinary screening program for anemia and ID in children and populationbased data on anemia, that includes ferritin concentration in children, continue to be limited. The aim of present study was to identify the prevalence of iron deficiency and explores their associations with socioeconomic parameters and it's complications in growth failure in and adolescents of 1-18 years old in Babol, Iran.

\section{MATERIAL AND METHODS}

In this cross-sectional study blood samples were collected from 100 children and adolescents ( 56 boys and 44 girls). They aged 1 to 18 years with growth failure including small height, low weight or both of them whom referred to our Hospital during years 2015-2016 were investigated. The patients were divided to 3 categories according to the place of life (urban, suburb, and rural). 70 individuals were urban patients (\%70), 24 rural patients (24\%) and 6 suburb patients (6\%).

The patient's weight and height were measured and compared according to growth curve indices (CDC) and patients with growth retardation (percentile of weight and height under 3\%) were evaluated for iron deficiency associated hematologic factors (blood hemoglobin level, MCV, and serum ferritin level). Other factors such as birth weight and the location of life were also evaluated in the patients. The exclusion criteria were patients with any associated disease such as heritable problems and liver-heart or kidney diseases, and also patients under treatment with iron were omitted from the study. Children with growth disorder having serum ferritin levels lower than normal (according to normal value associ- ated with age and sex) regardless to presenting anemia or not are considered as positive cases of the study.

\section{STATISTICAL ANALYSIS}

The $\mathrm{Hb}$ concentrations were symmetrically distributed. The distribution of plasma ferritin was skewed regarding higher values. The descriptive statistics included means, medians, interquartile ranges, and 95\% assurance intervals as appropriate. Student t-test or Chi-square tests were used to measure the dissimilarity between $\mathrm{Hb}$ and ferritin with clinical or other baseline features. Data statistical analyses was performed via SPSS software version 18.

\section{RESULTS AND DISCUSSION}

Anemia in little children lower than 2 years of age is of ultimate concern since their fast growth needs a high iron consumption which can be regularly not covered by their food plan, (Kotecha, 2011, Nguyen et al., 2017a). It was not possible to estimate the anemia prevalence in this group separately due to the minimal records. However, considering that approximately half the world wide population of preschool children are afflicted by anemia, with a prevalence as high as $64.6 \%$ in Africa and 47.7\% in Asia, and that we know anemia prevalence is higher in the group of children less than two years old, we could possibly assume that anemia in this specific age group is an essential global public health problem, mainly in low income countries(Mamabolo and Alberts, 2014, Ritu et al., 2017). According to previous studies in Iran, the prevalence of anemia between children is 15\% in this area (Sayyari et al., 2006).

Blood $\mathrm{Hb}$ levels were evaluated in patients to determine anemia prevalence between children with growth retardation. Ferritin levels among patients were measured to evaluate prevalence of iron deficiency between children with growth failure. Mid cell volume (MCV) of the patients was measured to evaluate the prevalence rate of microcytic anemia in growth retarded children and adolescents. Table 1 shows data about these variables.

Also these variables were investigated according to cut off points which is present in table 2 .

Anemia prevalence was defined between 4 different age groups and the results were shown in table 3.

According to Gomez et al., (1955) and Waterlow (1972) classification of undernutrition in children is rearranged in table 4 , the patients were divided in 3 categories (mild, intermediate and severe malnutrition). There was significant relation between serum ferritin levels and undernutrition. Serum levels of ferritin decreases with increasing undernutrition. 


\begin{tabular}{|l|c|c|c|c|}
\hline \multicolumn{6}{|c|}{ Table 1. Blood Hb, ferritin and MCV maximum and minimum rates } \\
\hline Variable & Maximum rate & Minimum rate & Average rate & Standard deviation \\
\hline Blood $\mathrm{Hb}$ & $13.9 \mathrm{gr} / \mathrm{dl}$ & $9.2 \mathrm{gr} / \mathrm{dl}$ & $11.8 \mathrm{gr} / \mathrm{dl}$ & 1.25 \\
\hline Ferritin & $180 \mu \mathrm{g} / \mathrm{L}$ & $5 \mu \mathrm{g} / \mathrm{L}$ & $43 \mu \mathrm{g} / \mathrm{L}$ & 36.6 \\
\hline MCV & $83 \mathrm{fm}$ & $69 \mathrm{fm}$ & $70 \mathrm{fm}$ & \\
\hline
\end{tabular}

Table 2. Variables according to cut off point

\begin{tabular}{l|c|c|c|c|}
\hline Variable & Cut off point & $\begin{array}{c}\text { Number of patients with } \\
\text { lower cut off point }\end{array}$ & percentage & $\begin{array}{c}\text { P value(between } \\
\text { two sexes) }\end{array}$ \\
\hline $\mathrm{Hb}$ & $<11.3 \mathrm{~g} / \mathrm{dL}$ & 37 & $37 \%$ & 0.028 \\
\hline ferritin & $<15 \mu \mathrm{L} / \mathrm{L}$ & 25 & $25 \%$ & 0.06 \\
\hline $\mathrm{MCV}$ & $<80$ & 29 & $29 \%$ & 0.08 \\
\hline
\end{tabular}

Anemia prevalence according to age associated normal $\mathrm{Hb}$ was $25 \%$ in boys and $41 \%$ in girls which was significantly different.

In this study we resulted that the prevalence of anemia in growth retarded children was 35.9\%. In a similar study, Anderson et al (Monchy et al., 2008) showed that the prevalence of anemia in children with growth failure in New Zealand was 71\%. They also resulted that microcytic anemia prevalence between the patients was $20 \%$ which matches with our results with $21 \%$ of prevalence. Anderson et al also resulted that $6 \%$ of children with growth retardation had lower ferritin levels than normal value. In the present study the prevalence of low ferritin levels was $1.6 \%$. Socio-economic status, indicated by place of life was an essential factor determining the risk of anemia.

In our survey, anemia was detected in $41 \%$ of the girls compared to $25 \%$ of the boys. Similarly, Kara et al and Yavuz et al also noticed a higher prevalence of anemia in girls compared with boys, (Kara et al., 2006, Yavuz et al., 2004). The lower incidence of anemia among pubertal boys might possibly be explained by the physiological surge in hemoglobin level triggered by sexual maturation and consequently by lowering the requirements after passing of the growth spurt. In girls, the phenomenon of menarche and menstrual irregularities reduce an expected age related increasing amount of hemoglobin concentration (Kara et al., 2006). The anemia found in this study was microcytic, hypochromic anemia, as showed by a low MCV. Anemia of this type has been known to be connected with iron deficiency(Torabizadeh et al., 2004).

The prevalence of anemia and iron deficiency in this study is much less than previous reports about normal kids from this age group in other regions of Iran as well as the reports of other developing countries (Akramipour et al., 2008, Hashizume et al., 2003), that indicates the important role of iron deficiency in growth failure of

\begin{tabular}{|l|c|c|c|c|}
\hline \multicolumn{6}{|l|}{ Table 3. Anemia prevalence in 4 different age groups } \\
\hline Age group & $\begin{array}{c}\text { Number of } \\
\text { Patients }\end{array}$ & $\begin{array}{c}\text { Percentage of patients } \\
\text { showed anemia based } \\
\text { on normal Hb }\end{array}$ & $\begin{array}{c}\text { Average } \\
\mu \mathrm{g} / \mathrm{dL}\end{array}$ & $\begin{array}{c}\text { Patients with ferritin } \\
\text { lower than normal value }\end{array}$ \\
\hline 6months- 2 years old & 11 & $42.8 \%$ & 38 & - \\
\hline 2-6 years old & 31 & $35 \%$ & 29.5 & - \\
\hline 6-12years old & 39 & $20 \%$ & 52.44 & - \\
\hline 12-18years old & 19 & $8.3 \%$ & 49.2 & $2(10.5 \%)$ \\
\hline
\end{tabular}

Table 4. Gomez and Waterlow malnutrition classification in children

\begin{tabular}{|l|l|c|c|c|}
\hline \multicolumn{2}{|l|}{ Grade of malnutrition } & Weight for age & Height for weight & Weight for height \\
\hline 0 & Normal & 190 & 195 & 190 \\
\hline 1 & Mild & $75-90$ & $90-95$ & $81-90$ \\
\hline 2 & Moderate & $60-74$ & $85-89$ & $70-80$ \\
\hline 3 & Severe & $<60$ & $<85$ & $<70$ \\
\hline
\end{tabular}


children. In addition, we cannot find any considerable correlation between hemoglobin level and serum ferritin revealing that iron status was not likely an essential determinant agent of anemia in the evaluated population. These results are actually in opposition to Hashismue et als study (Gomez et al., 1955). Brined et als study in Bangladesh (Briend et al., 1990) evaluated growth rate of 694 children from rural regions. They resulted that children drinking water with iron values more than $1 \mathrm{mg} /$ lit, were significantly higher than children drinking water containing less than $1 \mathrm{mg} /$ lit. They concluded that iron deficiency causes growth retardation of children in poor societies which in conformity with our study.

\section{CONCLUSION}

Since iron deficiency leads to growth failure in children through different ways such as decreasing oxygen transport capacity, decreasing energy production and decreasing appetite, blood iron levels monitoring in children is of great importance. The results of this study suggest that treatment of growth retarded children with iron supplements can improve their growth. Because data about prevalence of IDA in Iranian children is limited, we suggest further studies to be performed to define an average range of iron concentrations in accordance with other microelements such as zinc and copper in children in this area.

\section{AUTHORS' CONTRIBUTION}

Whole authors were in the same.

\section{FINANCIAL DISCLOSURE}

There is no conflict of interest.

\section{FUNDING/SUPPORT}

This study was financially supported by Student Research Committee, Babol University of Medical Sciences, Babol, IR Iran

\section{REFERENCES}

Akramipour, R., Rezaei, M., \&t Rahimi, Z. (2008). Prevalence of iron deficiency anemia among adolescent schoolgirls from Kermanshah, Western Iran. Hematology, 13(6), 352-355.

Bender, D. (2003). Do we really know vitamin and mineral requirements for infants and children? The journal of the Royal Society for the Promotion of Health, 123(3), 154-158.

Black, R. E., Victora, C. G., Walker, S. P., Bhutta, Z. A., Christian, P., De Onis, M., . . . Martorell, R. (2013). Maternal and child undernutrition and overweight in low-income and middle-income countries. The Lancet, 382(9890), 427-451.
Briend, A., Hoque, B., \&t Aziz, K. (1990). Iron in tubewell water and linear growth in rural Bangladesh. Archives of Disease in Childhood, 65(2), 224-225.

Domellöf, M., Braegger, C., Campoy, C., Colomb, V., Decsi, T., Fewtrell, M., ... Shamir, R. (2014). Iron requirements of infants and toddlers. Journal of pediatric gastroenterology and nutrition, 58(1), 119-129.

Gomez, F., Galván, R. R., Cravioto, J., \&t Frenk, S. (1955). Malnutrition in infancy and childhood, with special reference to kwashiorkor. Advances in pediatrics, 7, 131.

Hashizume, M., Kunii, O., Sasaki, S., Shimoda, T., Wakai, S., Mazhitova, Z., . . . Farmer, A. (2003). Anemia and iron deficiency among schoolchildren in the Aral Sea region, Kazakhstan. Journal of tropical pediatrics, 49(3), 172-177.

Kara, B., Çal, S., Aydogan, A., \&t Sarper, N. (2006). The prevalence of anemia in adolescents: a study from Turkey. Journal of pediatric hematology/oncology, 28(5), 316-321.

Kazal Jr, L. A. (2002). Prevention of iron deficiency in infants and toddlers. American family physician, 66(7), 1217-1224.

Kotecha, P. V. (2011). Nutritional anemia in young children with focus on Asia and India. Indian Journal of Community Medicine, 36(1), 8.

MacQueen, B., Christensen, R., Ward, D., Bennett, S., O'Brien, E., Sheffield, M., . . . Fleming, R. (2017). The iron status at birth of neonates with risk factors for developing iron deficiency: a pilot study. Journal of perinatology: official journal of the California Perinatal Association, 37(4), 436.

Mamabolo, R. L., \&t Alberts, M. (2014). Prevalence of anaemia and its associated factors in African children at one and three years residing in the Capricorn District of Limpopo Province, South Africa. curationis, 37(1), 1-9.

Monchy, D., Hem, N., \&t Hok, P. (2008). Co-existing micronutrient deficiencies among stunted Cambodian infants and toddlers. Asia Pacific journal of clinical nutrition, 17(1), 72.

Nguyen, P. H., Gonzalez-Casanova, I., Young, M. F., Truong, T. V., Hoang, H., Nguyen, H., . . . Ramakrishnan, U. (2017). Preconception Micronutrient Supplementation with Iron and Folic Acid Compared with Folic Acid Alone Affects Linear Growth and Fine Motor Development at 2 Years of Age: A Randomized Controlled Trial in Vietnam. The Journal of Nutrition, jn250597.

Nguyen, V., Wuebbolt, D., Thomas, H., Murphy, K., \&t D'souza, R. (2017). Iron Deficiency Anemia in Pregnancy and Treatment Options: A Patient-Preference Study [1L]. Obstetrics \&t Gynecology, 129, 122S.

Ritu, S., Ashok, D., Vithal, T. P., Shivani, R., \&t Rajaram, N. (2017). A Hospital Based Study on Anemia Prevalence in Children of an Indian Island. International Journal of Pediatrics.

Sayyari, A., Sheikhol Eslam, R., \&t Abdollahi, Z. (2006). Prevalence of anaemia in 2-12-year-old Iranian children.

Torabizadeh, Z., Naghshvar, F., KOUSARIAN, M., \& JAHANBAKHSH, R. (2004). The prevalence of iron deficiency related anemia in guid school students in Sari, 2002-2003. 
Victora, C., Adair, L., Fall, C., Hallal, P., Martorell, R., Richter, L., \&t Sachdev, H. (2008). Maternal and child undernutrition: consequences for adult health and human capital. Lancet, 371(9609), 302.

Waterlow, J. (1972). Classification and definition of protein-calorie malnutrition. British medical journal, 3(5826), 566.
Yavuz, T., Korkut, S., Yavuz, Ö., \&t Kocabay, K. (2004). Prevalence of anemia and iron deficiency anemia among adolescents in the western black sea region. Turkiye Klinikleri Journal of Pediatrics, 13(2), 711.

Ziegler, E. E., Nelson, S. E., \& Jeter, J. M. (2009). Iron supplementation of breastfed infants from an early age. The American journal of clinical nutrition, 89(2), 525-532. 